\title{
Emerging Leaders Project: Connecting University Resources to Community- Based Organizations Supporting Refugee Resettlement
}

\author{
Rosemarie Hunter \\ Kara Mileski
}

\begin{abstract}
In recent decades, populations seeking refuge have underscored the limitations of what have been standard approaches to resettlement. Shrinking resources, post-9/11 increase in security measures, and the diverse needs and assets of new arriving populations have exacerbated existing weaknesses in U.S. social service delivery systems and challenged neighborhoods inexperienced in these areas with complex issues of integration (Kerwin, 2011). In response to these issues, the University of Utah, the Utah State Refugee Services Office, and Salt Lake City Community College started an initiative to support the development of Community-Based Organizations (CBOs) and provide leadership and organizational training to existing leaders within these communities. The project created a shared space for community capacity building and integration as a twoway process. This paper will describe the formation and impact of the Emerging Leaders Project, a community-based participatory action research (CBPR) project focused on capacity building with new arriving communities in Salt Lake City.
\end{abstract}

Keywords: University-community partnerships, refugee resettlement, capacity building, community-based research

While the United States has resettled more individuals with refugee status than all other 13 members of the Organization for Economic Cooperation and Development (OECD) combined, the context of resettlement and the continuum of diverse needs across populations seeking refuge have significantly changed (Haddal, 2009). Since 1975, over $75 \%$ of U.S. refugee populations have come from Vietnam (and other parts of Southeast Asia) and the former Soviet Union (Singer \& Wilson, 2007). In recent years, the U.S. resettlement priorities have changed from large-scale special interest populations to smaller groups identified as being among the most vulnerable populations. This shift in focus has resulted in a broader range of diverse populations. At the same time, the post9/11 decade has seen an increase in security measure and limitations on programs and financial resources that previously supported immigrant and refugee integration (Kerwin, 2011).

The Office of Refugee Resettlement (ORR) provides the funding for refugee cash assistance (RCA) and medical assistance (RMA) for up to eight months after arrival in the U.S. Individuals must meet income and resource eligibility requirements and cannot be eligible for other temporary assistance programs such as TANF and Medicaid (Kerwin, 2011). With a focus on employment and self-sufficiency, federal programs are dependent on state refugee service offices and local resettlement organizations to achieve success. At the same time, local resettlement agencies and their partners are dependent on

Rosemarie Hunter, Ph.D., LCSW, is a Special Assistant to the President for Campus Community Partnerships at the University of Utah and Director of University Neighborhood Partners in Salt Lake City. Kara Mileski, MSW, is a doctoral student and graduate assistant at the University of Utah. This work was supported by the Lowell Bennion Community Service Center.

Copyright (c) 2013 Advances in Social Work Vol. 14 No. 2 (Fall 2013), 613-628 
securing other resources to fulfill their mission under State Department guidelines. During the first 90 days, resettlement agencies are already busy connecting families to other federal and state support programs. Once the initial benefit from the State Department's reception and placement has expired, the family is responsible for their own rent, food, health, and transportation needs.

In response to these issues, the Utah State Refugee Services Office (RSO) started an initiative to support the development of Community-Based Organizations (CBOs), also referred to as Mutual Assistance Associations (MAA) (i.e. United African Association, Sudanese Association of Utah, Somali Organization, etc.). The goals of these organizations are to provide a first response to the new arriving individuals and families and to act as an information, referral, and crisis response network connecting new arriving populations to existing resources and systems.

Training and empowering community leaders from each population are successful vehicles for reducing system barriers and supporting the whole community (Kretzmann \& McKnight, 1993). These individuals are already identified as leaders in their communities; therefore, they are often in the best position to understand the needs and strengths of their communities, the cultural issues involved, and begin from a space of trust and familiarity that many social service providers do not have. In this way, community-based ethnic leaders are the first contact for successful integration of new arriving populations that will ultimately connect new Americans to existing systems (Hunter, Mai, Hollister, \& Jankey, 2011). While community-based leaders come with a strong skill set, they too may lack an understanding of the resources and systems in the U.S. As a group, they have requested training on what systems and services are available to the community and appropriate ways of making referrals and accessing services. In addition, they are not familiar with how to organize and run associations and non-profits in the U.S. As part of this movement, the RSO has brought together community and university partners to develop partnerships that will support the training and leadership development for these community-based leaders.

\section{Context}

The Emerging Leaders Project was conducted within the framework of universitycommunity partnerships that emphasize the role of higher education to work in ways that are relevant to the communities where they are located (Maurrasse, 2001; Reardon, 2000). At the University of Utah, university-community partnerships are defined by tying community engagement to the academic cornerstones of research, teaching, and service. This approach to community engagement and scholarship values the community as a site of learning and community residents as holders of knowledge (Moll \& González, 1997). Similarly it provides multiple opportunities for higher education to be present with the community in addressing community-identified issues while still meeting its primary academic mission (Holland, 2005; Hunter, Munro, Dunn, \& Olsen, 2009).

University Neighborhood Partners (UNP), a university-community outreach partnership center and department of the University of Utah, is focused on building longterm collaborations between university departments, state and local government, non- 
profits, and social service systems of all kinds. Its mission is "to bring university and west side resources together for reciprocal learning, action and benefit...a community coming together” (University Neighborhood Partners, 2012).

UNP programs serve seven neighborhoods on Salt Lake City's west side. These neighborhoods comprise 15 census tracts. Almost 30\% of the city's total population lives in these neighborhoods (Perlich \& Li, 2013). The population in this area grew by $10.7 \%$, compared to $2.6 \%$ growth for Salt Lake City. Unlike the homogeneous neighborhood of rural Utah, $56.4 \%$ of the west side population is of minority background, which is $65.2 \%$ of the city's minority population. Over $46 \%$ of the population in west side neighborhoods is Hispanic. These 26,129 residents are $72 \%$ of the city's total Latino population (Perlich $\& \mathrm{Li}, 2013)$. The Latino population in the west side area grew by $32.4 \%$ between 2000 and 2010, compared to just $21.6 \%$ for Salt Lake City. Eighty-three percent of the city's Pacific Islander population, and $60.8 \%$ of the city's black population, live in the UNP target area (U.S. Census Bureau, 2010). In contrast, 31.6\% of the city’s Asian population, and just $20.4 \%$ of the city's white population live in this area (U.S. Census Bureau, 2010). Salt Lake City has also served as a preferred city for refugee resettlement with over 46,000 in the state and 1,000 new arrivals each year. Ninety-nine percent of individuals of refugee status in Utah live in Salt Lake Valley (Utah Refugee Coalition, 2013).

\section{Project Goals}

In Fall 2010, the University of Utah's Institutional Review Board approved the protocol for the Emerging Leaders Project. The first phase of the project, and the focus

of this paper, was to meet with community leaders of CBOs and other stakeholders to assist with the development of a leadership-training curriculum to support refugee populations with organizing their communities. The second phase of the project was to connect student learning to ongoing community capacity-building partnerships with these groups by building integrative engaged learning projects into a graduate level required course on social work community practice.

During Fall Semester 2010, we conducted focus groups with ethnic leaders and representatives of the Utah Refugee Services Office and local resettlement organizations to gain a better understanding of community needs and partners' goals. By connecting community-based research methods with models of leadership development, the project provided a vehicle for centering the knowledge of local leaders to inform curriculum development for the leadership trainings (Minkler \& Wallerstein, 2003).

Once the training materials were completed, the trainings were reviewed by a stakeholder curriculum committee and taught by a variety of community partners and faculty members currently involved with the new arriving populations. Leadership trainings were conducted at a community site identified by community partners and leaders. As the first group of leaders completed the training, they became involved with the future trainings and mentoring of new emerging leaders in subsequent years.

During Phase II of the project, the findings from Phase I were critical to informing the University of Utah Social Work Community Practice curriculum and connecting 
graduate students directly with communities of immigrant and refugee background. Beginning Spring Semester 2011, graduate students from the Social Work Community Practice course partnered with CBO leaders to conduct community assessments. Following the assessment phase, students worked in teams with identified leaders to develop and implement community action plans utilizing an assets-based approach (Kretzmann \& McKnight, 1993).

\section{Study Design and Methods}

Qualitative methods were used in order to better understand the effectiveness of the curriculum and current teaching methods, the dynamics of community leadership within these CBOs, and potential mechanisms for empowerment of these leaders. Qualitative methods further enhanced the ability for multiple sources of knowledge (from all partners) to be valued and understood in relation to creating holistic opportunities for leadership within a university-community partnership context (Denzin \& Lincoln, 2008; Minkler \& Wallerstein, 2003).

Action methodology was coupled with Community Based Participatory Research (CBPR) to provide support for issues of trustworthiness and value of the research (Maiter, Simich, Jacobson, \& Wise, 2008). As Herr and Anderson (2005) describe, the goals of action research are to (a) generate new knowledge, (b) achieve action oriented outcomes, (c) educate both researcher and participants, (d) generate results relevant to the local setting, and (d) create a sound and appropriate research methodology.

Overarching project goals sought to evaluate the current training and develop the curriculum with feedback from participants themselves in order to create curriculum that was relevant to populations in resettlement. In addition, the project sought to identify the priorities of the CBOs. Central to this investigation was to develop a better understanding of how individuals with refugee experiences could be supported in holding leadership roles in their own communities. The research questions for this study were:

RQ 1 - What are the strengths and weaknesses of the existing curriculum?

RQ 2 - What content areas need to be developed and included in the new curriculum?

RQ 3 - How could community leaders with refugee experiences be better supported in having leadership roles within their own communities?

RQ 4 - What community issues are of highest priority to community leaders and stakeholder participants?

RQ 5 - What curriculum and teaching methods are best suited to empowering ethnic community leaders from each population?

Focus groups were utilized in order to elicit a range of participant opinions. Similarly, the group dynamics allowed for reactions and conversations that could provide greater breadth and depth of conversation due to the diversity of participants (Mack, Woodsong, MacQueen, Guest, \& Namey, 2005). Focus group questions were developed in collaboration with a subset of CBO leaders who participated in early training programs and partnership development. The questions were provided in a semi-structured format. 
The goals of the interview/focus group questions were to guide the discussion in ways that kept it connected to the overarching research questions. Utilizing a capacity-building theoretical framework, qualitative data were shared with participants for the purpose of member checking and identifying and discussing major themes that surfaced. Peer debriefing sessions were conducted for the purpose of questioning and/or clarifying aspects of the inquiry that might otherwise remain only understood by the researcher (Lincoln \& Guba, 1985).

In addition to focus groups, the Principal Investigator (PI) collected observation data. The researcher attended the training sessions and maintained field notes in order to provide additional understanding of training context and experience. Observing and participating are integral to understanding the breadth and complexities of the human experience (Mack et al., 2005).

Participants for this study were 18 years old and older and included representatives of the State Refugee Services Office Curriculum Committee (RSOCC) and current leaders and members of local CBOs. Using flyers, emails, and project information meetings, participants were recruited from the list of attendees in the two previous training cohorts. The initial cohorts were entirely male, reflecting male dominant leadership in the CBOs representing refugee communities. Male-dominant leadership, the emerging nature of the CBOs, and traditional gender roles were all barriers to supporting gender equality in the CBOs during the formative years. However, in the most recent cohorts there has been an increase in female participants and conversations emerged that have been more inclusive and supportive of female participation in the CBO structure. This study was comprised of participants from the first two cohorts, involving 20 male leaders from community-based organizations (representing resettled communities from Africa, the Middle East, and Asia) and 5 members of the Curriculum Committee (1 woman and 4 men) of the Office of Refugee Services, Department of Workforce Services. Focus groups with curriculum committee members were conducted from a collaborative framework where participants serve as key informants to the research by reflecting and sharing history and past training experiences.

Two semi-structured focus groups were conducted with the leaders of the CBOs, resulting in a total of twenty participants ( 8 and 12 in each group, respectively). The purposes of the focus groups were to provide feedback about the previous training experiences and identify the strengths and weaknesses of the curriculum. In addition, participants were asked to discuss the priority needs of each of their communities and where they thought they required additional training and resources. The PI and a graduate student were available for the focus group and observations and participatory notes were taken at each of the interviews and focus groups.

During Spring 2011, study participants were invited to return for two additional focus groups that actively involved them in constructing the leadership-training curriculum and brainstorming around identified priority areas. These focus groups (action phase) had the primary purpose of bringing participants together to discuss next steps, recommendations, and suggested mechanisms for supporting leadership training - hence connecting methods to the goals of action inquiry wherein leaders have the time and space to develop 
potential solutions and recommendations. Figure 1 depicts Phases I and II of the project. The focus of this paper is Phase I.

Figure 1. Project Overview

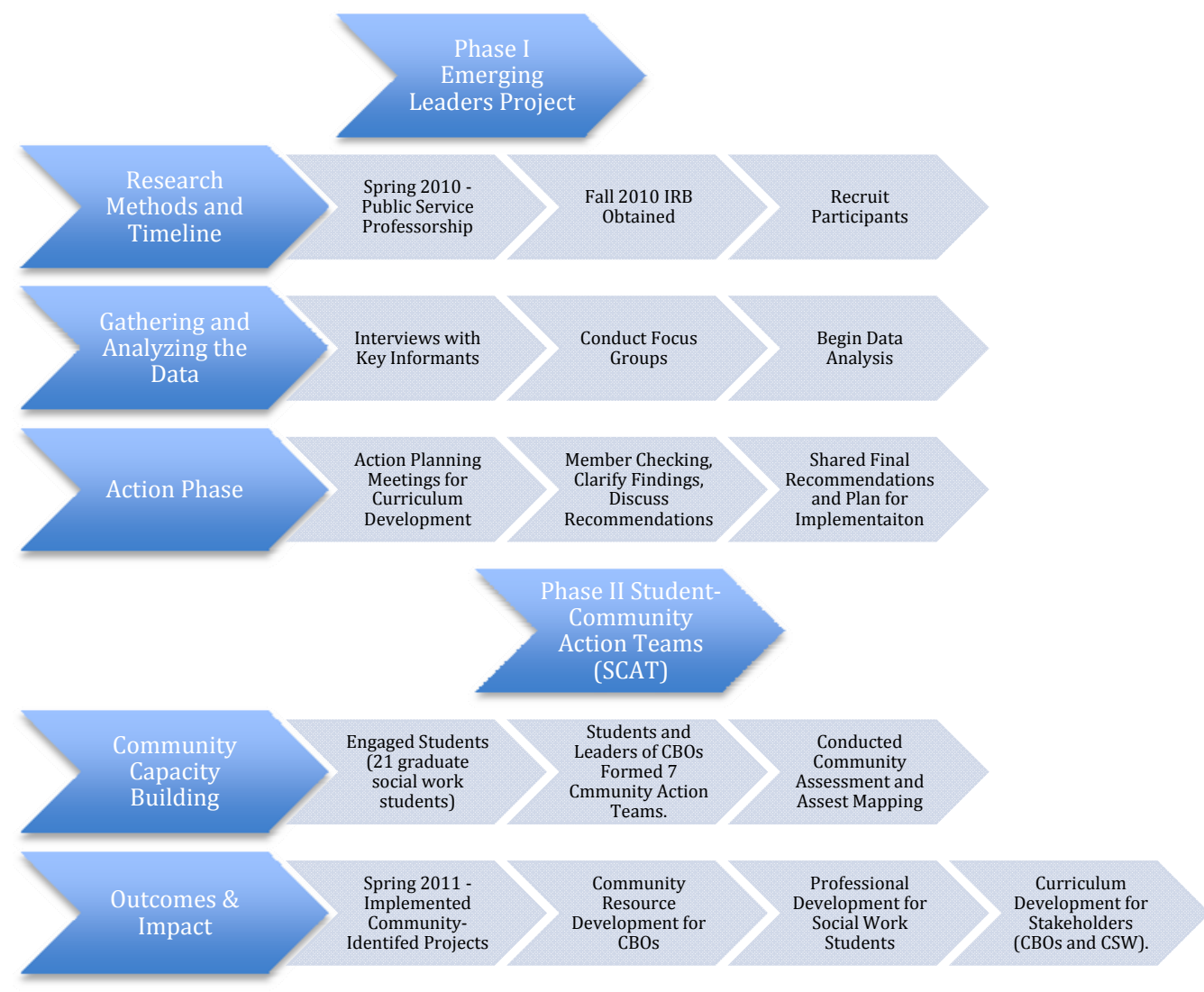

\section{The Curriculum}

The curriculum evaluated by community members was titled the Refugee Management Training Course (RMTC). This was a 15-week program that began with introductory material describing the reasons for organizing communities, including developing mission and vision for the organizations, as well as a series of steps for starting and managing a non-profit organization. While there was some content on organizing communities, the majority of the material focused on non-profit management, such as: organization mission and vision, the purpose of by-laws, board structure and governance, budgets, record keeping, grant writing, and fund raising. In addition, one unit on case management was included. The Office of Refugee Services and the Curriculum Committee initially defined the content for the first two cohorts. The course was taught once a week for 3 hours in an evening class format and dinner was provided. The grantwriting unit was taught in a half-day format on a Saturday morning. The Emerging Leaders Project was conducted in Year 3 of the program. 


\section{Findings}

\section{Focus Groups}

Importance of training. One of the initial findings of the study was that the participants were generally very positive about the content of the RSO supported trainings (RQ 1). They felt the content included important information and were all interested in learning more about how to organize and run non-profits that could support their communities. The leaders discussed how there were many gaps in the social service delivery systems and these micro-nonprofits were essential in assisting with resettlement of new arriving communities. The leaders were also in agreement that the content needed more information about how to organize their communities and get individuals involved as active members in the organization (RQ 2). For example, several of the participants had also attended the Westside Leadership Institute (WLI), a community-based training supported by the University of Utah and NeighborWorks Salt Lake. Based on an adaptive leadership model (Heifetz \& Linsky 2002), the WLI supports residents' efforts to take civic action for positive change in their communities (NeighborWorks Salt Lake, 2012).

Participants who had been involved in both trainings discussed the importance of connecting these programs in order to develop a more comprehensive skill set and a yearlong training experience. As leaders continued to discuss the need for community organizing skills, they shared that most new arriving populations were already organized according to tribal or regional communities in their native country. However, these same groups were now living throughout the valley and not able to easily connect with each other.

Case management. Focus group participants (CBO leaders) became very animated when discussing the unit on case management. There was a wide variety of reactions to having this topic as part of the training. For example, while all of the leaders expressed that one unit on case management training was not enough, some leaders went on to question if this was even an appropriate role for the CBOs. There seemed to be differing opinions around whose job it was to do case management: social service providers and resettlement organizations, or CBOs. Other leaders pointed out that it did not matter, as they were the ones who had community trust, access, and language capabilities. Even if they did not want to be case managers, in effect there was no way around this. Still for others, there were dual relationships when the leader of the CBO was also employed as a case manager by one of the resettlement organizations and worked with families in both settings. Comments included:

We have one class on case management. This should be a whole course! We need help.

We need help to better understand our role (as case managers)...we are responding to everything and often we do not have the necessary relationships in organizations to make referrals... and there is the issue of trust.

Our community expects us to take them to the doctor and to DWS and to register for school, so even if we do not want to be case managers, we have to. 
Sustainability and self-care. When examining how community leaders could be better supported in holding leadership roles within their own communities (RQ 3), complex issues of sustainability \& self-care were discussed. In order to provide greater access and distribute resources across several communities, the RSO supported one leader from each community to attend the training annually. The following year, a second member from each community would attend the training and so on (one from the Somali group, one from the Sudanese group, etc.) Focus group participants explained how these individuals would have to meet with their respective communities and try to explain what they were learning, and in effect spend a lot of time convincing the community that this was a good thing to do. Consequently, these individuals were spending a lot of time in class, followed by additional time with their community re-telling what they had learned in the training. Issues of sustainability were also tied to themes of self-care and burnout.

Building community capacity. Participants also expressed the need for more time to practice the new information they were receiving and needed more individuals in the community to be involved. Leaders of the CBOs who participated in the focus groups expressed great frustration and feelings of being overwhelmed with trying to address issues of resettlement and integration for their communities:

The skills and trainings are concentrated in a few people.... This causes many problems, we need to build the capacity of our whole community.

I am part of training teams, community workshops, adult education and I have a job! I cannot continue to do this, I have a family and they are paying the price. My community expects a lot of me, but I am only one person.

Youth and families. Supporting youth and families was identified as the highest community priority (RQ 4). Participants discussed how difficult it is for families to maintain their traditional roles. Adjusting to a new language and a new culture came at a great cost to family stability. Youth were learning English faster than their parents and at the same time, caught between different cultural norms.

The youth are out of control. There is a big problem with youth learning English and U.S. culture more quickly than parents and then they become the parents...or dominate and manipulative.

We have some youth threatening their parents that they will call the police on them because they do not let them do what they want.

We have trouble with our youth in almost every area. They are not fitting in at school and they are vulnerable to get in with the wrong groups.

These issues were tied to complications of resettlement, system barriers, and institutional racism. For example, as new arriving youth enter the school system they are placed at a grade level appropriate to their age. This placement often does not match their educational level and/or their language abilities. In other instances, participants shared stories of youth of refugee background who were academically strong and yet tracked into vocational programs rather than college preparatory courses. Below, participants shared similar frustration with accessing services: 
It is difficult to access services, understand schools, get jobs, transportation, housing. It is hard to get help if you look different and/or have an accent.

The youth are lost and we need to have more activities for them. ...we are different and we are treated differently...even me, I am here almost 10 years, I am a citizen, but when I walk into the school or the hospital, I am always a refugee.

Curriculum and teaching methods. Data related to RQ 5 identified curriculum and teaching methods that were best suited to empowering community leaders from each population. Focus group participants were in strong agreement regarding their recommendations to address concerns related to the process and methods of teaching the material. Community leaders shared that this was not only new material that required time to understand and process, the trainings also required new skills and they needed opportunities to practice these skills. To complicate matters, there were issues of language and literacy levels. While the eligibility criteria to participate in the trainings required a certain level of English, the participant language level was primarily evaluated on conversational English, or in some cases, by who in a particular community had the "most” English language skills. For example, when a particular group is newly arriving, this language ability may be relative to others in the community who have no English proficiency. Focus group participants' recommendations included:

The trainings are good, but we need more. They go quickly with one week on grant writing or bylaws.... We need time to practice, a place or person to go to and ask questions, somewhere to get feedback and advice.

Just because you show me how to write a grant one time does not mean I can write a grant.... I need you to do the grant with me and to do many, many grants together. Where can we go to ask questions and get help.... Of course this is the same with running the board and now I have to do home visits too...so let's first begin by writing a grant for a case manager.

I need them to go slower, I am translating in my head...also, and I do not know all the words and what they mean.

Language is a problem. I know most of the words...but not when you say them that fast and the teacher is constantly talking.... I need more time, I need to hear it again and again.... Sometimes I get stuck trying to understand one part and now they are on part 3 or 4 ...I am still at 1 . Writing and reading the material is slow....

\section{Participant Observations}

Language. Data collection during participant observations corroborated the themes identified by the focus group participants. For example, participants' attentiveness was markedly different in training sessions that were interactive, including hands-on team work or role play as opposed to those that were content-heavy, with a lot of technical language, using power points as the main instructional method. In addition, throughout the training sessions, it was necessary for instructors or peers to "break down the 
English" by providing more examples, using words other than those listed on the worksheets. Also, where possible, peers provided translation. While there were many different languages and dialects present across the group, there were opportunities to use a common language such as Arabic, French or Burmese across several groups.

Interestingly when meeting with members of the RSO curriculum committee, they did not identify language issues as a concern; however, they did express concerns that the content contained new concepts that many participants were being exposed to for the first time:

Participants are having difficulty applying what they learned and staff (of the $R S O)$ often need to go over much of the material on a more individual basis.

For many participants these concepts are totally new and this is their first time trying this.

Remember, many of these leaders come from countries that had corrupt government, so the idea of having a Board of Directors is a totally foreign concept.

Teaching methods. Participant observation provided several insights into teaching methods that are best suited to empowering this group of community leaders. For example, throughout the course when participants were invited to share their experiences, this almost always resulted in storytelling. These stories served as powerful teaching tools, allowing participants to switch from student to teacher. Similarly, participants embraced any opportunity to share information about their native countries, culture, and tradition. Cultural preservation was a dominant theme during the training sessions. Even for those participants who had lower English literacy levels, when given the opportunity to use art illustrations or symbols, they created a visual story map that shared their history and hopes for the future.

Because a different instructor taught each session, it was easy to observe how teaching styles affected participant learning. Active teaching methods that incorporated art, role play, partner or small group work were preferred and appeared to provide additional support for a participant with beginning English language skills. Collaboration and competition also served as effective methods for empowering leaders. Working together in small groups was effective to divide tasks and get more accomplished, while small group presentations provided accountability and set high expectations across groups.

\section{Action Phase}

During the Action Phase, study participants reviewed the findings of the data and applied this information to re-construct the leadership training curriculum. As previously mentioned, overall, the curriculum content was perceived as satisfactory; however, there were two recommendations specific to content areas. The remainder of the group recommendations focused on teaching methods and ways to incorporate more skillbuilding activities into the curriculum. The following recommendations were identified by the participants and submitted to the curriculum committee. 


\section{Curriculum Recommendations}

1. Community Organizing - Participants were in agreement that there needed to be content, and likely a different training course, on community organizing. Inclusion of the WLI as the first training content was recommended.

2. Case Management - Leaders were unanimous that there was a need for more case management training. However, they remained in disagreement about the role of CBOs in providing these services. The group recommended that a different case management curriculum be developed and a larger conversation regarding the role of CBOs be facilitated with the RSO Advisory Board.

\section{Teaching Methods Recommendations}

1. Lead Teacher - While the participants were supportive of keeping multiple instructors, as this assisted them with establishing more relationships and networks for ongoing support, they suggested that there be a lead teacher who would be responsible for, and attend, the whole training. This would provide for greater consistency and integration of learning objectives across the curriculum.

2. Case Studies - Participants discussed that they had many case examples they needed assistance with that could serve as suitable teaching examples. Similar to this was the idea that one organizational case could be used throughout the course.

3. Interactive Teaching Methods - The participants' valued opportunities for applied learning and also to work on their own organization's task. Rather than completing a fictional grant application, they recommended time to work with instructors on current grant opportunities.

4. Training Community Teams - Participants expressed that much would be gained if they could attend the trainings as community teams (4 - 5 individuals from each group). This would provide opportunities for greater organizational capacity building and teams could make actual progress on the needs of the organization.

5. Mentoring and Ongoing Support - While the leaders gain much from these trainings, they expressed that the real challenge came when trying to apply what they had learned. They recommended having mentors who would be willing to assist them with applying these concepts and available for consultation and support.

The following year, the majority of these recommendations were implemented and several, such as the case management discussion, are still underway. As a result of the leaders' input, the resettlement agencies are now providing an extended case management period of up to two years for new arriving populations.

\section{Areas of Mutual Learning}

The project provided strong opportunities for mutual learning and action. Indeed, both CBPR and university-community partnerships prioritize reciprocity and mutually 
beneficial outcomes. At a very fundamental level, trusting relationships were developed and social capital extended. For example, as participants became more familiar and comfortable with the research process, they also became more active in meetings and with wanting to engage with the data. As themes emerged, they were ready and wanting to move toward action. Similarly, the PI's role changed, moving from researcher and teacher to consultant, facilitator, and assistant. Social capital and networks grew at all levels. For example, several participants were interested in access to higher education for themselves and family members. They utilized their growing relationships with the academic partners to build new networks. The PI also saw growth in social capital within the communities of refugee background and the addition of new relationships that moved from individual to family and community, while often enjoying a wide range of flavorful cuisine. As trust and mutual learning grew, a strong presence of mutual responsibility emerged.

There was also new learning at the academic institution. For example, in response to the concerns regarding the need for case management training, representatives of the College of Social Work (CSW) met with leaders of CBOs, representatives of the Office of Refugee Services, and local resettlement organizations to develop case management trainings that could be utilized by multiple social service organizations across the valley. In the past, the CSW offered a Human Service Worker certificate program; however this has not been available for over a decade. These stakeholders formed a subcommittee and are in the process of updating the curriculum and plan to offer this certificate program beginning in Fall 2013.

Similarly, the recommendation for mentoring and ongoing support has stimulated the development of a non-profit incubator project at the university. This is a partnership between University of Utah, the CSW, the Department of Public Administration (PA) and Utah Nonprofit Association. Still in its pilot stage, the project represents a new structure for the academic institution and includes matching graduate students from the CSW with CBOs to conduct community needs assessments and asset mapping. During the second semester, CBOs partner with graduate students from PA who assist them with building the capacity of their organizations. This also provides opportunities for interdisciplinary practice across social work and public administration. The University of Utah offers a dual degree program in these disciplines, although students from these two disciplines seldom engage in shared practice in the field.

\section{Discussion and Future Research}

While this project was conducted with specific goals of connecting the university resources (teaching and research) to community-identified priorities for reciprocal action, the data has engaged new conversation and complexities around identifying the role of these CBOs serving communities of immigrant and refugee populations. While the need for additional support in assisting with resettlement and integration is obvious, whose responsibility is this? At the same time, focus group participants were clear that they wanted to play a role in assisting their communities with integration, but they had differing views on what approach would best achieve this. For some leaders, the need to serve as first responder to new arriving populations was a priority and indeed several 
leaders expressed that this could not be done effectively without participation of the CBOs. Other leaders shared that ideally they want to be supporting their communities through cultural preservation activities, such as native language instruction for youth, classes in traditional dance, and understanding the historical and political issues related to their migration.

Importantly, and as a result of utilizing a CBPR framework, discussions regarding gender equity surfaced during the research process. For some participants this was a new area and often not included as part of organizational management, as management was not viewed as a traditional female role. However, with other members there was an increasing awareness of the need to include and address women's issues, yet there was disagreement around whether this meant including women or just "women's issues." These gender issues have a complex context including historical and cultural issues becoming naturalized over time. Nevertheless, conducting a CBPR project with the leaders of the CBOs created a space of inquiry where these questions could surface. Indeed, the third year cohort experienced the inclusion of female participants, and the Office of Refugee Services organized a Women's Committee with representation of women from a variety of diverse communities. It will be important to continue this research with more meaningful involvement of female community leaders and participants. Including dialogues on gender awareness and active participation in the $\mathrm{CBO}$ structure is a priority for future research and mainstreaming gender perspectives.

Additional areas for future research surfaced when examining how to best support community leadership. These comments focused around leaders who felt isolated and overwhelmed in their roles. As the conversations evolved, however, it was clear that these comments also surfaced larger questions related to individual versus collective societies. How could these communities benefit from a more inclusive approach to these trainings? What are opportunities for growing understanding on both sides, allowing for two-way integration? While the leaders are learning new information and skills, how are U.S. systems involved in these relationships, incorporating new knowledge gained in ways that improve social service delivery? If resettling populations are changed as they integrate, are host societies also not changed? How is this information changing how we practice?

Even more complex were discussions about who is leader? Participants discussed the role of elders in the community as traditional leaders and the need for board members to include elders in their decision making process. Of course, this was not entirely supported by the organization by-laws; nevertheless, this traditional role of positional power was active in many of these organizations and added to the confusion and frustration of leaders and community members.

Finally, two additional areas requiring more investigation were issues of trust and gatekeeping. When the CBOs experienced conflict or confusion, the community would hold the leader responsible. While this may not be true in all organizations, the ethnic leaders associated this experience with the way things were back home. Participants expressed how corruption in their native countries and inside refugee camps had an effect on how resources were distributed. Leaders shared stories of how government and 
refugee camp leaders served as gatekeepers and often required additional compensation for the distribution of basic resources. When things here did not go as expected by community members, the CBO leaders were suspected of leading the organization for personal gain. These doubts and conflicts added to the feelings of frustration on the part of the leaders.

\section{Conclusion}

The privilege of assisting diverse communities' integration into the fabric of U.S. society comes with the responsibilities of applying the new knowledge gained in ways that benefit community well-being. Building on the work of Kretzman and McKnight (1993), the major contribution of the Emerging Leaders Project is to reaffirm that the solutions to community issues begin with the community itself. This asset-based framework separates place and circumstance from individual and community capacity. It thinks of new ways to incorporate the talents of people and the culture of the community with the existing issues and opportunities (Morse, 2011).

The Emerging Leaders Project reminds us that resettlement is an ongoing process and does not end with arrival to a new country. Understanding integration as a two-way learning process necessitates that host societies embrace resettlement as an opportunity to evaluate and change system practices that are no longer effective. Similarly, this project demonstrates the power of university-community partnerships as effective vehicles for investing university resources in issues relevant to local stakeholders while simultaneously developing valuable teaching and research opportunities.

\section{References}

Denzin, N. K., \& Lincoln, Y. S. (2008). Introduction: The practice and discipline of qualitative research. In N. K. Denzin \& Y. S. Lincoln (Eds.), Strategies of qualitative inquiry: The SAGE handbook of qualitative inquiry ( $3^{\text {rd }}$ ed., pp. 1-44). Thousand Oaks, CA: Sage Publications, Inc.

Haddal, C. C. (2009). Refugee and Asylum-Seeker Inflows in the United States and Other OECD Member States. Washington, DC: Congressional Research Service. Retrieved from http://www.ntis.gov/search/product.aspx?ABBR=PB2009107176

Herr, G. L., \& Anderson, K. (2005). The action research dissertation: A guide for students and faculty. Thousand Oaks, CA: Sage Publications.

Heifetz, R. A., \& Linsky, M. (2002). Leadership on the line: Staying alive through the dangers of leading. Cambridge, MA: Harvard Business School Press.

Holland, B. A. (2005). Reflections on community-campus partnerships: What has been learned? What are the next challenges? In P. Pasque, R. Smerek, B. Dwyer, N. Bowman, \& B. Mallory (Eds.), Higher education collaboration for community improvement and engagement (pp. 10-17). Ann Arbor, MI: National Forum on Higher Education for the Public Good, School of Education, University of Michigan. Retrieved from http://www.thenationalforum.org/Docs/PDF/Wingspread_05_Final_Monograph.pdf 
Hunter, R., Mai, T., Hollister, L., \& Jankey, O. (2011). A university-community partnership model for capacity-building and collective learning with individuals of immigrant and refugee experience: The example of the Hartland Partnership Center. Journal of Global Social Work Practice, 4(1). Published online May/June 2011. Retrieved from http://www.globalsocialwork.org/vol4no1/Hunter.html

Hunter, R., Munro, S., Dunn, L., \& Olsen, K. (2009). Bridging university and community: The power of collaborative partnerships for social change. In K. Mohrman, J. Shi, S. E. Feinblatt, \& K. W. Chow (Eds.), Public universities and regional development (pp. 289-311). Sichuan, China: Sichuan University Press.

Kerwin, D. (2011). The faltering US refugee protection system: Legal and policy responses to refugees, asylum seekers, and others in need of protection. Washington, DC: Migration Policy Institute.

Kretzmann, J., \& McKnight, J. (1993). Building communities from the inside out. Chicago, IL: ACTA Publications.

Lincoln, Y. S., \& Guba, E. G. (1985). Naturalistic inquiry. Newbury Park, CA: Sage Publications.

Mack, N., Woodsong, C., MacQueen, K. M., Guest, G., \& Namey, E. (2005). Qualitative research methods: A data collector's field guide. Research Triangle Park, NC: Family Health International.

Maiter, S., Simich, L., Jacobson, N., \& Wise, J. (2008). Reciprocity: An ethic for community-based participatory action research. Action Research, 6, 305-325. doi: $10.1177 / 1476750307083720$

Maurrasse, D. J. (2001). Beyond the campus: How colleges and universities form partnerships with their communities. New York, NY: Routledge.

Minkler, M., \& Wallerstein, N. (Eds.). (2003). Community-based participatory research for health. San Francisco, CA: Jossey-Bass.

Moll, L., \& González, N. (1997). Teachers as social scientists: Learning about culture from household research. In P. M. Hall (Ed.), Race, ethnicity and multiculturalism: Policy and practice (Vol. 1, pp. 89-114). Columbia, MO: University of Missouri.

Morse, S. (2011). Communities revisited: The best ideas of the last hundred years. National Civic Review, 100, 8-17. doi: 10.1002/ncr.20042

NeighborWorks Salt Lake. (2012). Westside Leadership Institute. Salt Lake City, UT: Author. Retrieved from http://www.nwsaltlake.org/community-building/20-westsideleadership-institute

Perlich P. S., \& Li, D. (2013) Community data for policy, planning, and community investment: Salt Lake City case studies. Utah Economic and Business Review, 73(1), 1-11. Retrieved from http://www.bebr.utah.edu/Documents/uebr/UEBR2013/UEBR2013no1.pdf 
Singer, A., \& Wilson J. H. (2007, March). Refugee resettlement in metropolitan America. Migration Information Source. Washington, DC: Migration Policy Institute. Retrieved from http://www.migrationinformation.org/feature/display.cfm?id=585

Reardon, K. M. (2000). An experiential approach to creating an effective communityuniversity partnership: the East St Louis Action Research Project. Cityscape: A Journal of Policy Development and Research, 5(1), 59-74.

United States Census Bureau. (2010). Census 2000 Gateway. Washington, DC: Author. Retrieved from http://www.census.gov/main/www/cen2000.html

University Neighborhood Partners. (2012). Home. Salt Lake City, UT: University of Utah. Retrieved from www.partners.utah.edu.

Utah Refugee Coalition. (2013). Retrieved from http://utahrefugeecoalition.wordpress.com/13-2/frequently-asked-questions/

\section{Author note:}

Address correspondence to: Rosemarie Hunter, Ph.D., Ph.D., LCSW, Director, University Neighborhood Partners, 1060 South 900 West, Salt Lake City, UT, 84104. Email: r.hunter@partners.utah.edu. 